\title{
The Everyday Life Uncertainties of HIV/AIDS Diseased Bodies in the Era of HIV/AIDS Treatment in Kenya
}

\author{
Eric R Masese ${ }^{1, *}$, Ednah N Masita ${ }^{2}$ \\ ${ }^{1}$ Department of Sociology and Psychology, Moi University, Eldoret, Kenya \\ ${ }^{2}$ Department of Anthropology and Human Ecology, Moi University, Eldoret, Kenya
}

Copyright $\odot 2018$ by authors, all rights reserved. Authors agree that this article remains permanently open access under the terms of the Creative Commons Attribution License 4.0 International License

\begin{abstract}
Since the advent of HIV/AIDS more than four decades ago, the disease has continued to be constructed as "imminent death". This has made the experience of being diagnosed with the disease a traumatic life event in one's life project. Although overtime the disease has come to be conceptualized as a chronic illness through treatment using antiretroviral therapy, the reality of eventual mortality in the face of chronicity makes those infected to represent lived bodies suffering existential disruption. Using illness narratives from 20 respondents living with HIV/AIDS, selected using snowball sampling techniques, this paper shows the ambiguity of social construction of HIV/AIDS as a manageable chronic illness, and at the same time as an imminent death in everyday life. This ambiguity is evidenced by the strategies that people living with HIV/AIDS use in resisting the perception of their condition as a death sentence and at the same time trying to (re)negotiate their threatened identity due to stigma within the larger community they live in. This paper then argues that stigma still remains a major social problem among those living with HIV/AIDS despite the advancement in HIV/AIDS treatment. This is evidenced from illness narratives, which emphasize on personal transformation, social support and the search for normality as key strategies of dealing with limitations imposed by the HIV/AIDS illness in attaining culturally recognized markers of personhood in an individual life project.
\end{abstract}

Keywords HIV/AIDS Stigma, HIV/AIDS Treatment, Illness Narratives, Personhood, Lived Experiences

\section{Introduction}

In the postmodern era, the human body has assumed a great focus in interdisciplinary studies. This has been necessitated by fundamental changes in how our bodies are organized and experienced in everyday lives. Initially, the body was understood from the biomedical paradigm which construed it as a fixed biological bounded entity which is immune to nature and can only be understood through empirical rules of biological science [1]

This understanding is contrary to the [2] assertion that the body is an experiencing entity which is shaped by particular historical moments. As an experiencing entity, memory plays a big role in making judgement of what one feels and what one thinks about his or her body through an analytical reflection of past experiences in a given context. This makes an individual's experience of his/her body to be subjective.

Sandstrom, K [3] argues that feelings, thoughts and actions towards our body are mere expressions of our lived experiences. These experiences are based on personal subjective interpretations and evaluation of everyday life. This makes the body both as an object which we can feel and act on; and as a subject which we can observe and talk about. In this regard, it is through our body that we exist, act and understand the world.

Merleau-Ponty, [4:223] notes that we do not understand ourselves first as pure ego, but with the bodies in which we locate ourselves, that is "by the time we are in a position to ascribe experiences to subjects at all, whether ourselves or others, we already understand them in primitive bodily terms". The body is thus not a mere thing, not a discrete object of outer perception but "a quasi-object that an essentially disembodied ego has or owns as the locus of its subjective sensations" [ibid]. For Merleau-Ponty, we do not have our bodies; rather, we are our body, that is, we are in the world through our body insofar as we perceive the world with our body.

In addition, [5] posits that the body is an empirical embodiment of the self and because selfhood is symbolic, embodiment therefore represents the personification and materialization of otherwise invisible qualities of personhood. This then means that the body and experiences of embodiment are central to our sense of being, who we think we are, and what others attribute to us.

Brooks P. [6] further asserts that the body is a text which can serve various meanings in everyday life. It is a signifier 
or the place in which messages are written. For example, when a particular body is contrasted against another for symbolic effect, there is meaning which is being communicated about those bodies. These meanings, however, are relative to specific socio-cultural contexts.

In everyday life, human beings live and tell narratives about their life. These narratives are based on their lived bodies and are a way of creating meaning for their everyday existence. Though they are based on individual lived bodies, they are always in relation to others in specific socio-cultural contexts. In most cases these stories illuminate individual experiences within a specific social, cultural and institutional context where these narratives are constituted, shaped, expressed and enacted [7].

Narratives about lived bodies are ways that individuals make sense of their everyday existence. It is a symbolic resource enlisted in dealing with human suffering and how to deal with it. They not only show how individuals create and recreate themselves through narratives but also how they are actively involved in addressing their suffering [8]. Narratives also help in revealing struggles in recreating the self and the past especially when the future is highly uncertain or even threatened.

Though narratives are important in understanding lived bodies, they are not a transparent rendition of reality. Instead they are seen as a creative interpretation of the past, generated in specific contexts of the present. To understand and make sense of the narratives people tell about their lived bodies, we must contextualize them to a specific socio-cultural context that has shaped and continued shaping their lives [8].

In the discourse of illness and health, narratives about the body at the level of lived experiences have heightened awareness of bodies as vulnerable entities with the potential to sicken and suffer $[9,10]$. These narratives give a glimpse of tension and a connection between the living body and the material lived body through embodied experiences of reality. This tension is more pronounced in HIV/AIDS illness.

Since HIV/AIDS was discovered in early 1980s in Kenya, the disease has continued to be constructed not only as an "imminent death" but also as a symbol of pollution and social contamination - a metaphor for "spoilt identity". This has made the experience of being diagnosed with the disease a traumatic life event in one's life-project. Those infected with the disease have come to represent lived bodies suffering existential disruption due to possible limitations imposed by the disease. These limitations compel those infected to calibrate a new life story, a new character or a way of being-in-the world which demands existential reorientation [11].

Though over time the disease has come to be conceptualized as a chronic illness, the reality of living with a "spoilt identity" and eventual mortality in the face of chronicity makes those infected vulnerable. This makes those living with HIV and AIDS to experience isolation, embodiedness and anxiety causing acute existential disruption and meaninglessness as they "assert their individuality through ultimate demise" [12].

People living with HIV/AIDS have their own personal experiences of their lived bodies. These experiences are best articulated through their everyday narratives on how their life and bodies negotiate the limitations imposed by the illness. This paper thus looks into what shapes these illness experiences among people living with HIV/AIDS in everyday life at a time when access to HIV/AIDS treatment has greatly improved.

\section{Method}

To explore the experiences of the lived bodies of HIV/AIDS, in-depth conversational interviews with open-ended questions were used to collect data from 20 respondents who were living with HIV/AIDS. The respondents were selected using snowball sampling techniques and their sample size determined through saturation method. An interview guide which addressed the respondent's experiences and daily life activities in relation to HIV/AIDS infection was used. The respondents were asked to describe their lived experiences in relation to their past, present and future concerns.

Before each interview, verbal consent was sought from all respondents after they were fully briefed about the purpose of the study, the kind of questions they would be asked and their right to decline to participate in the study; to withdraw at any stage or decline to answer to any enquiry which they felt uncomfortable with. In addition, respondents were assured that they would remain anonymous and their information would not be revealed to anyone else. All the interviews were tape recorded.

The narratives from in-depth conversational interviews formed a large corpus of data analysis. These narratives were taken as discourses that not only transferred information on lived experiences of people living with HIV/AIDS but also indicated what individuals or cultures can accomplish through language.

Audio taped narratives from in-depth conversational interviews were first transcribed ad verbatim to ensure that all emerging issues were captured during analysis. Individual transcripts were then read and re-read several times to identify key themes, which were then noted. Similar themes together with their supporting verbal quotes, from all interviews were grouped together to facilitate easier analysis.

To understand the lived experiences of people living with HIV/AIDS, all the narratives from the respondents were analyzed using hermeneutics methodological framework. In this case, each respondent's narrative was examined in relation to other respondents' narratives. In addition, the analysis utilized [13] notion of "symbolic senses" to examine symbolic use of language and the 
common metaphors that respondents used in reference to their lived experiences with HIV/AIDS infection. All the themes that emerged consistently in most narratives were noted. Themes which were unique were also noted. These themes were then shared with some of the respondents who participated in the study to determine if they were a true reflection of what they said. After this, the themes were used to discuss the lived experience of people living with HIV/AIDS.

\section{Findings}

\section{Existential Disruption and Meaninglessness}

Being diagnosed with HIV/AIDS is one of the most traumatic life experiences in an individual's life. This experience is generated because of uncertainty in one's biography due to the weakening or dissolution of standardized expectations of life development in a particular society. HIV/AIDS diagnosis thus represents a radical discontinuity to one's life path.

The social construction of HIV/AIDS as a biographical uncertainty has been propagated by biomedical, media and lay discourses. These constructions mostly present a linear and mortal trajectory of AIDS, collapsing the time between diagnosis and death such that HIV seropositive status is presented as a death sentence. This has given birth to apocalyptic narratives which present HIV/AIDS diagnosis as a forward march to impending death despite the use of antiretroviral therapy which over time has challenged this construction as evidenced by a 34-year-old graduate teacher, Mr. Kamau:

......after finishing my bachelor's degree in education, I was extremely lucky. I was recruited as a teacher and posted to one of the best schools in Kenya. The salary was good. I saw myself building my life and career with ease. I thanked God for the favour he had on me. After four years of teaching, lady luck struck me again. I was selected for a scholarship to advance my career in Europe. I was really excited. As I was processing my travel documents, my life was unmade! .... I was diagnosed with HIV/AIDS. This meant that I was as good as dead. I saw no need of either living or building my career. I wanted to die. Though I was aware that the use of antiretroviral therapy would help me to live a longer and healthier life, the shame of living with a stigmatizing illness was too much to bear........waking up every day knowing that I am one of the HIV victims! I knew my past sexual life especially as a university student was not good, but I never imagined it would lead to this...... even after changing my way of life.

Mrs. Kemunto, a 25-year-old married lady also narrated how HIV/AIDS disrupted the worthiness of her body as a woman because of the forced sterilization she underwent due to HIV/AIDS diagnosis:

I was diagnosed with HIV when attending an antenatal clinic. I did not share this information with my husband because he was likely to accuse me of infecting him with the virus. The doctor who diagnosed me advised that I must give birth at the hospital through caesarean section to avoid infecting my unborn child. ....... On the day I started experiencing labour pains, I went to the hospital and was admitted. The doctor gave me a form to sign. He never allowed me to read it. I was taken to theatre where I delivered a baby girl through caesarean section. I stayed in the hospital for five days to recuperate. One year later, I wanted to have another child, preferably a boy. So, I went to a private clinic for advice given my HIV status. The doctor in this private clinic carried out some tests on me and informed me that I could not conceive because my uterus was removed during my last delivery .... This information hit me like a thunderbolt... It was worse than when I was told I had HIV! I saw myself as a very useless woman, dying without a son to inherit my property and carry on my lineage! I hated myself and contemplated suicide.

Mr. Juma, a 36-year-old mechanic was diagnosed with HIV when he was donating blood for his brother who was involved in an accident. Few months later, Juma developed some complications which caused him to get paralyzed on the right side of his body. This made him to discontinue working as a mechanic. As a result, he entirely depended on his wife to provide for him and the family. This made him to devalue himself as a man.

HIV/AIDS diagnosis was also found to create social disorder and anxieties among HIV/AIDS diseased bodies because its transmission lies at the heart of the pathways of social reproduction. This makes it problematic for these diseased bodies to engage in social reproduction because sexuality is inextricably intertwined with social reproduction. Social reproduction in this context is the process by which people in a particular community perpetuate themselves and their identities from generation to generation. For example, Mr. Morara, a single university graduate aged 26 years discovered that he was HIV positive during a recruitment exercise as a policeman. Though he was professionally counseled that he could lead a normal life and have children who were HIV negative through medical assistance, he was in a dilemma on what to do with regards to getting married. He didn't know how he would disclose his HIV seropositive status to his potential partner without injuring his own reputation, and protect his partner from infection, and at the same time make her conceive. He was also worried of who would take care of his children if he died while they were young. Mr. Morara's dilemma was made worse by the fact that he was 
of age and the society expected him to marry and have children who would carry on his lineage.

This experience of social disorder and anxieties among HIV/AIDS diseased bodies was, however, worse among women especially those who were not married as narrated by Ms. Nyabiage, a 30-year-old primary school teacher:

\begin{abstract}
........immediately after college, I was posted as a teacher not far from my home. To minimize expenses, I decided to stay at my parent's house. All was well until I was diagnosed with HIV. When my parents knew of my status, they forced me out of our home. My mother told me that I was an embarrassment to them ......at my age I should have been married because younger girls than me had gotten married and were happily living with their husbands. She informed me that if I were married, I wouldn't have been infected with HIV. My father informed me that his home was not a cemetery for outsiders and more so for those dying from sinful diseases. I had no option but to seek for a transfer to a school far from home. Since I left home almost two years ago, neither my parents nor any other close relatives have bothered to inquire about my welfare.
\end{abstract}

Among married couples with children, an HIV/AIDS diseased body was found to be a threat to their identity as good mothers or fathers. Ms. Nyabonyi, a 37-year-old mother of five children narrates:

As parents it is very difficult to meet the needs of our three children adequately. This has been made worse because of our ill health due to HIV. It really pains us to see our children sleep hungry and unable to attend school due to lack of school fees. Our eldest daughter is also involved in sexual relationships with older men. As parents we don't have a face to advise her against these relationships........ We fear discussing with her any topic touching on morality and illness due to our HIV status...... We have failed totally as parents!

Ms. Nyabonyi's experience was also shared by Mr. Jomo, a 29-year businessman:

My major concern is about the future of our children. I am sure that sooner than later my wife and I will die from this shameful disease which has no cure. Our children will become orphans ....... they will not have anyone to care for their needs. To make matters worse, I do not have a moral authority to guide them in issues of morality! This virus has destroyed my life and that of my family!

However, not all individuals experienced HIV/AIDS diseased bodies as a threat to their identity. Instead, infection with HIV/AIDS was seen as a mere disruption of their everyday life due to the limitations imposed by the illness. This experience was common among individuals who had experienced "a hard life" prior to HIV diagnosis and therefore never bothered to bracket off the illness as a means of protecting their identity. The life story of a 24-year-old woman called Ms. Chayo underscores this:

I was born in a family of three children. My mother was a single mother. Given that women in our community do not inherit land from their parents, my mother was forced to move to an urban area in order to fend for us. In town, we resided in a single room where my mother was engaged in selling illicit brew. The income from this activity was not enough to meet our basic needs, so she supplemented it by engaging in sexual activities with some of her clients. ........ The whole of our lives entailed living with uncertainty.... Sometimes my mum would be beaten by her clients and raped in front of us! This kind of life became normal to us. One day when a client slept in our house...... I was about 13 years or so.... after having sex with my mum, he came to where I was sleeping and raped me. I called for help from my mother but she was dead asleep. After the incident, my mother woke up and chased him away. I later learnt that the rape incident was my mother's plan because the man paid her more money. Since then she encouraged me to have sex with her clients as a way of supplementing our family income. Later, my mother was diagnosed with HIV and died of AIDS related complications. This meant that the responsibility of taking care of my two siblings was left to me. I had no other source of income, and had to continue with my mother's business. ...... In this business my philosophy was living one day at a time. This is because in more than three occasions, I almost lost my life through injuries I sustained after fighting with some clients. The last incident which saw me admitted for three months also led to my diagnosis of HIV. This was not a surprise to me! I am now sick and unable to engage in my business fully rendering me almost a beggar. I am now dependent on people for my sustenance and that of my siblings.

Mr. Okioma, a 34-year-old man and a father of three narrated how he was socially discriminated and rejected because his HIV/AIDS diseased body was seen as signifying contagion and pollution:

When I moved from town to our rural home with my family, I noticed that most people were not at ease whenever I interacted with them. I comforted myself that they were not used to me given my long stay in town. However, one day on my way to town to buy some medicine, I bordered a bus which was almost full. Suddenly, most passengers alighted and only four passengers remained. I did not understand what was happening until the driver came to me in anger and told me to alight because nobody wanted to travel in the same bus with me for fear of me infecting them with HIV. I really felt devalued especially when I got 
off the bus and everybody started shouting at me that I should desist from looking for people to infect with my HIV and instead seek forgiveness for my immoral ways.

The experience of social rejection and discrimination was not restricted to those infected with HIV only but also to their immediate family members. Mr. Masumbuko, a 43-year-old secondary teacher elucidates:

In school my children are not allowed to play with other children. Most parents have cautioned the school administration not to allow my children to be in close contact with theirs. Some parents have threatened to withdraw their children from the school if their demands are not met. The school administration has instituted various measures such as allocating my children specific seats in class, plates and cups, etc. so that they do not share anything with other children.

The experience of discrimination and social rejection especially from the significant others was found to cause loss of self-esteem due to self-devaluation. Mr. Mariera, a secondary school graduate teacher aged 43 years argues:

I look at myself and wonder why a highly educated man like me would engage in unprotected sex with commercial sex workers whenever I went out for entertainment! I never lacked anything at home.......my wife, is very young and beautiful, yet here I am infected with AIDS! I feel so dirty and unclean. I really regret my former lifestyle. All my friends do not want to associate with me. Even some members of my family do not want to associate with me too.

\section{Mending Diseased Bodies in Everyday Life}

As observed from the foregoing illness narratives, it is clear that HIV disease imposes a heavy toll to the existing diseased subjects. This makes people living with HIV/AIDS to alienate themselves from the outside world as a way of cushioning themselves from stigma and oppressive structures. This destabilizes and undermines their sense of self-worth as existing beings.

Consequently, those living with HIV/AIDS are forced to come up with new ways of living cognizant of the limitations imposed by the illness. This is demonstrated by the narrative of a former commercial sex worker called Ms. Susan aged 24 years:

I had worked as commercial sex worker for about six years. It was not my wish to be in this trade but the need to provide for my three children as a single mother. Over the years I had seen a number of my colleagues die from HIV/AIDS. I knew my time would come as I was involved in this dirty job. One day I went to hospital for treatment of a recurring skin infection. The doctor recommended an HIV test which turned out to be positive. Though these results were not a surprise to me, the thoughts of leaving my children alone in this world really bothered me. I knew nobody would take care of them because of my immorality! I had to change my way of life. I decided to quit this trade and have nothing to do with men! I joined one of the evangelical churches where I confessed my sins and got saved. As a Christian I believe that God would heal me from this illness. I am now a member of a group of preachers who spread the word of God to those who are not saved. I find this a higher calling than anything else in my life.

As observed from the narrative above, Ms. Susan reworked on her "spoilt identity" by stopping her trade as a commercial sex worker and getting saved. As noted, her religious conversion in an evangelical church had profound implications on her identity; one, her confession of her past sins and asking God for forgiveness is believed in evangelical churches to discard the past spoilt identity and bring forth a new 'good identity', two, her believe in the miracle of healing creates hope of restoring her health from HIV/AIDS illness, and three, her involvement in religious activities marks a new beginning of doing moral activities for the benefit of the society. All this fortifies her new identity.

Other respondents dealt with the disruptive nature of HIV/AIDS on their lived bodies by going public about their HIV seropositive status and assuming the role of a "moral career patient" Goffman [14]. Mrs. Nyankoni, a 25-year-old female teacher had gone for a prenatal check-up and was diagnosed with HIV. This information devastated and shocked her given that she had just been married for less than a year and was three months pregnant.

When she went home, she wanted to share this sad and shocking news with her husband. However, she lacked the courage to do so. A few days later while cleaning the house, she found some hidden medicine. She was already on antiretroviral treatment (ARV) drugs and so she knew exactly what the drugs were for. On inquiry from the husband, he admitted that he was HIV positive and had been on ARV treatment for a while, but was afraid of telling her because he was afraid of losing her. This confession really broke her heart. She wouldn't understand how a person who confessed undying love for her would deliberately infect her with HIV. She wouldn't fathom living with HIV/AIDS and dying from it. She contemplated committing suicide but ruled it out because it would emotionally affect her immediate family.

As days went by, she and her husband lost a lot of weight and they were soon the subject of gossip in the village. This caused them to be stigmatized and socially excluded. Despite this, she continued following the doctor's advice and taking her medicine. Three months later, while attending a prenatal clinic, she met a counselor who had lived with HIV for 15 years. The counselor convinced her that HIV diagnosis was not a death sentence and one could 
lead a normal life and give birth to HIV free children. This really encouraged her and three months later, she gave birth to an HIV free baby boy.

Although Mrs. Nyankoni accepted her situation and was living positively, her husband was emotionally stressed. He indulged in alcohol and refused to take his medication as recommended by the doctor. He later died of AIDS related complications. The demise of her husband ushered in floodgates of accusations. She was accused of infecting her husband with HIV and consequently was rejected and socially excluded by her in laws and other members of her family. She was the subject of gossip in her village. She was forced to close the small shop she was running since all the customers fled. When she sought refuge at her local church, people there also ignored her.

Alone and dejected, Mrs. Nyankoni decided to confront the situation on her own. Since she had accepted her HIV seropositive status and knew that it was not a death sentence, she embarked on educating people about HIV/AIDS. This brought an end to the gossips. Noting how successful this strategy was, she became more aggressive in organizing talks to various groups about HIV/AIDS as a way of fighting the stigma and empowering people on how to avoid risk of infection, and how to live positively for those who were already infected.

With time her efforts were recognized not only in her village but far and wide. This made her a role model in the community. In all public functions she was given an opportunity to talk about HIV/AIDS as a way empowering the community. She undertook various short courses on HIV/AIDS in order to equip herself with more knowledge about the disease. This drastically gave her a lot of respect in the community to the extent that she was nicknamed the "Doctor of AIDS".

Another respondent, Alex, a 28-year-old man had just secured a job in a tea factory as an administrator. The salary was good and he rented a house near his work place. One year into the job, he became seriously sick and was admitted in a nearby hospital. Initially the doctor thought he had acute malaria and typhoid. After a few days of treatment there was no improvement. The doctor recommended a series of tests including HIV. All the other tests turned out to be negative except that of HIV. This shocked Alex so much. Not in his wildest dreams did he ever imagine to be HIV positive.

Since his CD4 count was low, he was put on antiretroviral therapy (ART) immediately. The fact that he was medically covered by his company insurance, his sickness became known to his workmates. People delved into his personal life until everyone knew that he was HIV positive. After recuperation, he went back to work. At the workplace, he felt socially rejected as there was a lot of gossip about his life. He really felt betrayed by his workmates. He could not take the humiliation anymore and decided to resign and move to a new place where he was not known. He hence opted to use his middle name which was not common to many people. This way he cushioned himself from social stigma.

Other research participants coped with their HIV/AIDS diseased bodies by taking on an ambivalent view of the HIV illness through the process of redefining the illness in a language that plays down its negative implications. In this case, the accuracy of the biomedical aspects of the disease is not contested, but the social explanations or justification of the illness trajectory is overemphasized. Mr. Kayaga, a 42 , year old man was experiencing various complications from HIV illness. He explained each of them independently and tried to justify why they were happening at that particular time:

For a month I had this persistent cough because of this dry spell. I took medicine which made me to have severe diarrhoea. This made me lose a lot of weight. At least now I have started regaining. I think my spending most of the time in bed has made my body to react to the new beddings my wife bought recently. This has caused me to have skin rashes.

Mr. Osinde, 27-year-old Driver who was asymptomatic coped with his HIV/AIDS diseased body through a cognitive process of redefining it as "almost healthy," that is between the normal and the sick:

The doctor told me I have HIV and not AIDS. This means I am almost healthy and can continue with my everyday activities provided I avoid risky behaviours like having sex with commercial sex workers. So as long as I watch my behaviour, I won't be sick.

\section{Discussion}

This study examined how people living with HIV/AIDS experience the illness and how they cope with its imposed limitations. Findings show that the way people respond and cope with life threatening illnesses is shaped by both biography and culture in a given context. This was reflected by how illness narratives were used by those living with HIV/AIDS to (re)negotiate the disruptiveness in their lived bodies through personal transformation and social support so as to fit in the expected life of normalcy in a given cultural context. This makes the illness narratives people tell about their lived life to be mere reflections of the dominant social, cultural, economic and political discourses which govern everyday life [11, 15, and 16].

As noted from illness narratives in this study, stigma still remains a major social problem of those living with HIV/AIDS. This is in spite of the fact that the disease has moved from being a fatal to a chronic illness due to advancement in treatment using Antiretroviral Therapy (ART). At individual level, the notion of visibility and corporeality were central to the phenomena of HIV/AIDS stigma. This arose when HIV/AIDS diseased bodies were negatively contrasted due to their failure to meet the 
culturally expected standard of life project as collectively defined, due to the limitations imposed by the disease on an individual lived life.

These culturally expected standards of a life project were socially constructed as core in attaining the expected personhood. Personhood in this context entails the attainment of physiological, psychological and social competence of a fully functioning and accepted member of society. The attainment of personhood was marked by culturally recognized markers throughout the life project of an individual. These markers were but not limited to engaging in parenthood (fatherhood and motherhood) through social reproduction, performing effectively culturally defined gender roles and avoiding social death.

The limitation imposed by HIV/AIDS illness in attaining these markers of personhood compounded the existential dilemma of those living with HIV/AIDS by destabilizing and undermining their sense of self as existing beings. This forced them to undergo existential reorientation by calibrating new ways of living as a way of achieving a sense of cultural, social and moral belonging to their social networks [17].

Consequently, these new ways of life were primarily determined by the perceived socio-cultural benefits of HIV self-disclosure or non-disclosure in relation to meeting the culturally recognized markers of personhood. For example, those who felt that HIV self-disclosure would help them achieve a sense of cultural, social and moral belonging to their social network used overt strategies such as going public about their HIV seropositive status by assuming the role of a "moral career patient", while others used the strategy of breaking from the past and living a virtuous life". However, those who felt that HIV self-disclosure would further lead to stigmatization and discrimination used covert strategies such as managing their HIV seropositive status through self-denial (ambivalence).

These socio-cultural benefits of HIV self-disclosure or non-disclosure were found to be mediated by gender power relationships. As noted in this study, due to women's subordinate, social and economic status relative to men, they used overt strategies which were hinged on HIV self-disclosure to protect themselves from further abandonment and violence. However, men used covert strategies which were based on HIV non-disclosure as a way of protecting their social identity and status. This shows that a combination of hegemonic masculinity and perceptions of personal invulnerability act to undermine the processes of men's HIV/AIDS risk construction and appropriate behaviour change [18]

Globally, HIV/AIDS treatment using ART has changed the disease from being a fatal to a chronic illness. As a chronic illness, those infected can live longer and pursue their life projects as long as they adhere to their treatment regime. However, this was found not to influence the diseased subjects' behaviour or action towards the
HIV/AIDS treatment. Instead the perceived social benefits of HIV/AIDS treatment in enabling the diseased subject to meet the culturally recognized markers of personhood in their cultural life project played a critical role. Although these culturally recognized markers were collectively defined, they were chronologically ranked in terms of importance by each individual in time and space. This relative ranking of cultural markers of personhood therefore determined the behaviour or action of those living with HIV towards HIV/AIDS treatment. This shows that everyday behaviour (action) of those living with HIV/AIDS was not influenced by biomedical information as communicated in HIV/AIDS campaigns. Instead it was determined by social relationships as collectively determined by social and moral discourses governing personhood.

\section{Conclusions}

HIV stigma remains a major social problem facing those living with HIV/AIDS. This is evidenced by every day strategies used to deal with the limitations imposed by the illness in meeting culturally recognized markers of personhood in a life project. These strategies are mediated by gender power relationships and determined by the socio-cultural benefits of HIV self-disclosure or non-disclosure. These socio-cultural benefits transcend the biomedical benefits and are evaluated in terms of how such actions enhance the social relationships of people living with HIV within their social cultural networks. Therefore, efforts to address HIV stigma such as HIV/AIDS treatment among those living with HIV/AIDS should incorporate culturally recognized markers of personhood in their approach, as a way enhancing their social acceptability within their network.

\section{NOTES}

COMPLIANCE WITH ETHICAL STANDARDS

\section{Conflict of Interest}

All authors of this manuscript report no conflicts of interest.

\section{Ethical Approval}

All procedures performed in studies involving human participants were in accordance with the ethical standards of the institutional and/or national research committee and with the 1964 Helsinki declaration and its later amendments or comparable ethical standards. 


\section{Informed Consent}

Informed consent was obtained from all individual participants included in the study and the names used are pseudonyms.

\section{REFERENCES}

[1] Shilling, C.The body and social theory. London: Sage publications, 2003

[2] Jager A, Tewson A, Ludlow B, Boydell K. Embodied ways of telling storying of self: A systematic review of body-mapping. Forum: Qualitative social research Vol 17 No 2, 2016

[3] Sandstrom, K. The lived body experience from adults with cerebral palsy. Clinical Rehabilitation 21:432-441, 2007

[4] Taylor C. The body, in Husserl and Merleau-Ponty. Philosophical Topic Vol 27 No 2 Pp 205- 226, 1999

[5] Waskul, D and Plate, R. For home and freedom. Nairobi: Kenya Literature Bureau, 2011

[6] Brooks P. Body works: Objects of desire in modern narrative. Cambridge, Massachusetts: Harvard university press, 1993

[7] Clandinin, D and Rosiek,. Mapping a landscape of narrative inquiry: Borderland Spaces and tensions. In D. J. Clandinin (Ed.), Handbook of narrative inquiry: Mapping a methodology. Thousand Oaks, CA: Sage, 2006

[8] Marita, E. Stories as lived experience: Narratives in forced migration research. Journal of refugee studies Vol 20 No 2, 2007

[9] William, S. Medical sociology and biological body: Where are we now? Health $10(1): 5$-30, 2003

[10] Young, I. On female body experience: "Throwing like a girl" and other essays. Oxford university press, 2005

[11] Kleinman,A. The Illness Narratives: Suffering, Healing and the Human Conditions. Basic Books, 1998

[12] Markotic, N. Re/Presenting disability and illness: Foucault and $20^{\text {th }}$ century fictions. Disability quarterly. 23(2): $178-192,2003$

[13] Ricoeur, P. Existence and Hermeneutics (Translated by Kathleen McLaughlin). In J. Bleicher Contemporary Hermeneutics: Hermeneutic as method, philosophy and critique PP 236-256. London: Commonwealth secretariat. 1980

[14] Goffman, E.Stigma: Notes on the management of spoiled identity. New York: Prentice-Hall,1990

[15] Foucault, M. Discipline and punishment: The birth of the prison. New York: Vintage books, 1995

[16] Murphy, T. Testimony, In T Murphy and Poirier (Eds.). Writing AIDS: Gay literature, language and analysis. New York: Columbia UP, 1993

[17] Dilger, H. The power of AIDS: kinship, mobility and the valuing of social and ritual relationships in Tanzania. African Journal of AIDS Research, 2006

[18] Ganle, J. K. Hegemonic masculinity, HIV/AIDS risk perception and sexual behaviour change among young people in Ghana. Qualitative Health Research 26 (6) 763-781, 2016 